
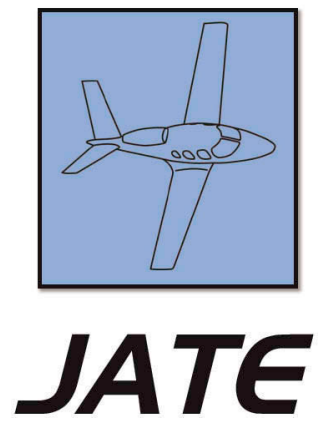

Journal of Aviation Technology and Engineering 5:2 (2016) 51-68

\title{
Quantitative Risk Evaluation of Obstacle Limitation Surfaces for Final Approaches at Airports
}

\author{
Amila Silva and Alexandre G. de Barros
}

(University of Calgary)

\begin{abstract}
Obstacle limitation surfaces (OLS) are the main safeguard against objects that can pose a hazard to aircraft operations at and around airports. The standard dimensions of the most of those surfaces were estimated using the pilot's experience at the time when they were included in the standard documents. As a result, some of these standards may have been overestimated, while others may not provide an adequate level of safety. With airports moving to the Safety Management System (SMS) approach to design and operations safety, proper evaluation of the level of safety provided by OLS at specific sites becomes important to airport operators. Therefore, this study attempts to collect actual flight path data using information provided by air traffic control radars and to construct a methodology to assess the probability of aircraft deviating from their approach path. This will be helpful to estimate safe and efficient standard dimensions of the OLS and assess the risk level of objects to the aircraft operations around airports. The methodology is presented using the aircraft trajectories of approaches at Ottawa International Airport (CYOW). Estimated dimensions of Code 3 approach surfaces also are presented.
\end{abstract}

Keywords: obstacle limitation surfaces, aviation safety, quantitative risk analysis

\footnotetext{
About the Authors

Amila Silva is a graduate student in the Department of Civil Engineering at the University of Calgary, Canada. He completed a master's degree in transportation engineering at the University of Moratuwa in Sri Lanka. His research interests are transportation safety, airport engineering, and transportation planning.

Alexandre G. de Barros is an associate professor in the Department of Civil Engineering at the University of Calgary, Canada. He received his MSc in operations research and transportation in 1994 from the Instituto Tecnológico de Aeronáutica, Brazil, and his PhD in transportation engineering in 2001 from the University of Calgary. He has several years of experience both in academia and in industry, where he worked as a consultant in transportation planning and airport planning and engineering. He also is the former director of the Airport Infrastructure of the Brazilian National Civil Aviation Agency. He has several publications in aviation, airports, and traffic safety. His research interests are highway design and safety, airport safety, and airport design standards.
} 


\section{Introduction}

Aerodrome design standards are the main framework used for planning and design of airport facilities. They were established over 60 years ago in order to maintain safe aircraft movements at and around aerodromes. Obstacle limitation surfaces (OLS) are part of aerodrome standards. They are a set of imaginary surfaces defined at and around airports to protect airborne aircraft operations from obstacles that can pose a hazard to their movements. Most often, those safety surfaces extend well beyond the airport property and, as a result, certain areas around airports are considered as integral parts of the aerodrome environment (ICAO, 1983). Furthermore, OLS are identified as an important design standard affecting the orientation of the runway system layout.

Internationally agreed standards for airport design were established as Annex 14 to the Chicago Convention on Civil Aviation (ICAO, 1999). However, each country uses its own standards for planning criteria related to aerodromes. Although most of those national standards are based on Annex 14, some countries may elect to develop and adopt their own standards. AC 150/5300-13 in the USA (FAA, 2004), TP 312 in Canada (Transport_Canada, 1993), and CAP 168 in the United Kingdom (CAA, 2011) are examples of national standards used in different countries. In all those standards, shapes and dimensions of the OLS and their objectives are defined. A careful review of those standards reveals that there are some differences in dimensions and shapes of OLS among those documents. For instance, in contrast to the trapezium shape longitudinal cross section of obstacle free zone (OFZ) prescribed by the International Civil Aviation Organization (ICAO), a rectangular section is defined in Federal Aviation Administration (FAA) standards (FAA, 2004). Generally, aviation safety organizations allow deviations from these standards when designing the airfields, if the designer can prove that an adequate of level of safety is achieved.

According to ICAO (1983), the significance of any existing or proposed objects to the safety of aircraft operations within the aerodrome boundary or vicinity of the aerodrome is assessed by the use of two separate sets of criteria defining airspace requirements. Obstacle limitation surfaces are the main standard defined in Annex 14 to minimize the collision risk of airborne aircraft near airports. The second set of criteria comprises obstacle assessment surfaces (OAS), also known as PANS-OPS surfaces (ICAO, 2006; Litesheim \& Xiao, 2006). The main purpose of PANS-OPS surfaces or OAS is to provide guidance for procedure designers to estimate the obstacle clearance height $(\mathrm{OCH})$ in an airport and assess the risk of obstacles near the runways. $\mathrm{OCH}$ is the height at which aircraft can initiate a missed approach in a low visibility condition when it uses the instrument approach procedures. Pilots are only allowed to descend below this level if they have clear sight that the aircraft is correctly aligned with the runway and there are sufficient visual cues to continue the approach.

The height of the objects that penetrate the OAS surfaces, the characteristics of aircraft, and navigation facilities at a runway are used to calculate its $\mathrm{OCH}$ using the OAS. The OAS consists of six sloping plane surfaces whose shape and dimensions are determined by linear equations. The coefficients and constants of those equations are available in the PANS-OPS OAS software provided by ICAO.

In coming years, it is expected that air transportation will experience greater growth than what has been observed during the last decade. With this expected traffic growth, airports will need to expand their facilities to increase aircraft operation capacity (Hall et al., 2008). In such situations, it may be impractical or impossible to meet the requirements of existing OLS standards due to space limitations at and around airports. As a result, airports may have to use new dimensions for the OLS and check the level of safety of the modified surfaces.

A thorough review of the literature has identified very few studies done to justify the level of safety of existing or modified OLS standards, plus a few studies that were carried out to measure the level of safety of OFZs using simulated flight paths (Eddowes, Hancox, \& MacInnes, 2001; ICAO, 2005b). Recently, studies done by Fricke and Thiel (2013) assessed the level of safety provided by OLS and PANS-OPS using the radar data. The methodology presented in their studies did not consider the dependency between the lateral and vertical deviation data that significantly affects the analysis results. Other studies have focused on the flight path deviation analysis (Thiel \& Fricke, 2010; Thiel, Seiß, Vogel, \& Fricke, 2012). Marco and Auria (2014) analyzed the flight trajectories generated with 6 degrees of freedom $(6 \mathrm{DoF})$ flight simulations and developed a methodology to calculate the collision risk with objects near airports. The analysis was based on the simulated flight paths generated by Monte Carlo simulation. Cramer and Rodriguez (2013) studied the path steering error (PSE) effect on the calculated lateral aircraft deviation. PSE is defined as distance from estimated aircraft position to a beam point on the lateral computed path. In that study, the effect of the total system error on the calculated aircraft deviation was studied. There also are computer programmes such as SAT-P, PDToolKit (MITRE, 2015) available commercially to identify the hazardous obstacles with respect to the existing standards.

In the 1960s, a joint effort by the FAA's flight standards organization and ICAO's obstacle clearance panel (OCP) developed the collision risk model (CRM) for instrument landing system (ILS) operations. The main objective of this model was to determine the area that needed to be protected when an aircraft is making an ILS approach. This model is 
Table 1.

Approach surface dimensions. Source: ICAO, 1999.

\begin{tabular}{|c|c|c|c|c|c|c|c|c|c|c|}
\hline \multirow{3}{*}{ Surface and dimensions } & \multicolumn{4}{|c|}{$\begin{array}{l}\text { Non-instrument } \\
\text { code number }\end{array}$} & \multicolumn{3}{|c|}{$\begin{array}{c}\text { Non-precision approach } \\
\text { code number }\end{array}$} & \multicolumn{3}{|c|}{$\begin{array}{c}\text { Precision approach } \\
\text { category }\end{array}$} \\
\hline & \multirow{2}{*}{1} & \multirow{2}{*}{2} & \multirow{2}{*}{3} & \multirow{2}{*}{4} & \multirow{2}{*}{1,2} & \multirow{2}{*}{3} & \multirow{2}{*}{4} & \multicolumn{2}{|c|}{ Cat I } & \multirow{2}{*}{$\frac{\text { Cat II, II }}{3,4}$} \\
\hline & & & & & & & & 1,2 & 3,4 & \\
\hline Length of inner edge (m) & 60 & 80 & 150 & 150 & 150 & 300 & 300 & 150 & 300 & 300 \\
\hline Distance from threshold (m) & 30 & 60 & 60 & 60 & 60 & 60 & 60 & 60 & 60 & 60 \\
\hline Divergence (each side) & $10 \%$ & $10 \%$ & $10 \%$ & $10 \%$ & $15 \%$ & $15 \%$ & $15 \%$ & $15 \%$ & $15 \%$ & $15 \%$ \\
\hline \multicolumn{11}{|l|}{ First section } \\
\hline Length (m) & 1600 & 2500 & 3000 & 3000 & 2500 & 3000 & 3000 & 3000 & 3000 & 3000 \\
\hline Slope (m) & $5^{0}$ & $4^{0}$ & $3.33^{0}$ & $2.5^{0}$ & $3.33^{\circ}$ & $2^{0}$ & $2^{0}$ & $2.5^{0}$ & $2^{0}$ & $2^{0}$ \\
\hline \multicolumn{11}{|l|}{ Second section } \\
\hline Length (m) & NA & NA & NA & NA & NA & 3600 & 3600 & 12000 & 3600 & 3600 \\
\hline Slope (m) & NA & NA & NA & NA & NA & $2.5 \%$ & $2.5 \%$ & $3 \%$ & $2.5 \%$ & $2.5 \%$ \\
\hline \multicolumn{11}{|l|}{ Horizontal section } \\
\hline Length (m) & NA & NA & NA & NA & NA & 8400 & 8400 & 8400 & 8400 & 8400 \\
\hline Total length (m) & NA & NA & NA & NA & NA & 15000 & 15000 & 15000 & 15000 & 15000 \\
\hline
\end{tabular}

still being used to assess the risk of obstacles below the decision height (DH) in ILS operation by aviation authorities. The main shortcoming of the model is that it can only be used to analyze the ILS approaches. Therefore, it only considers the instrumental errors of the ILS system. However, deviation due to aircraft characteristics, pilot techniques, and weather condition are ignored in the model (ICAO, 1980).

It was found that in most recent studies related to airport standards, the dimensions of a safety standard can vary with respect to the geographical location of an airport and local weather condition (Eddowes et al., 2001). Therefore, it is more cost effective if an airport can estimate the required dimensions of OLS according to their local weather and geographical conditions. The expected move in the United States and Canada to a Safety Management Systems (SMS) approach to airport regulation (ICAO, 2012) confirms this perception. To address this rising issue, this study proposes a methodology to estimate the probability of aircraft deviation from standard flight paths using actual flight trajectories. Moreover, an extension of the methodology can be used to estimate the dimensions of the OLS that provide the acceptable level of safety for aircraft operations. The analysis is presented using the aircraft trajectories at Ottawa International Airport (CYOW). As an example, approach surface dimensions for ICAO Code 3 instrument and non-instrument were estimated and compared with the existing OLS and PANS-OPS surface dimensions.

According to ICAO (1999), the objective of the approach surface is to protect the aircraft when approaching a runway. Its dimensions depend on the aircraft code number and the approach category. The aircraft code number mainly represents the kinetic energy of an aircraft on final approach, using the aircraft's reference field length as a proxy. The approach category represents the type of approach (i.e., visual or instrument, precision or nonprecision) according to weather conditions and available navigation instruments. The standard dimensions and geometric shape of the approach surface are shown in Table 1 and Figure 1.

To the best of our knowledge, there are no studies publicly available that explain the rationale for the ICAO standards presented in Table 1. By analyzing actual aircraft trajectories, one can estimate the probability density functions of deviations from the standard flight path. These probability density functions can then be used to determine the risk of a collision between an aircraft and objectsexisting or hypothetical-located in the proximity of the aircraft's path. Such analysis can then be used both to determine the level of safety at existing airports and to set risk-based standards for the design of new facilities. This paper discusses a methodology to collect data on aircraft trajectories and evaluate these deviation probability distribution functions using data collected at CYOW.

\section{Acceptable Risk or Target Safety Level (TLS) for Aircraft Operations}

The main reason for developing a safety standard is to provide an acceptable level of safety to aircraft operations. An acceptable level of safety is defined with respect to the risk for aircraft operations. According to the Civil Aviation Authority of Sri Lanka, safety risk is defined as "the assessment, expressed in terms of predicted probability and severity of the consequence(s) of a hazard taking as reference to the worst foreseeable situation" (CAASL, 2010). The worst foreseeable situation can vary with respect to the phase of the aircraft operation. For example, aircraft can collide with an object when taxiing or 


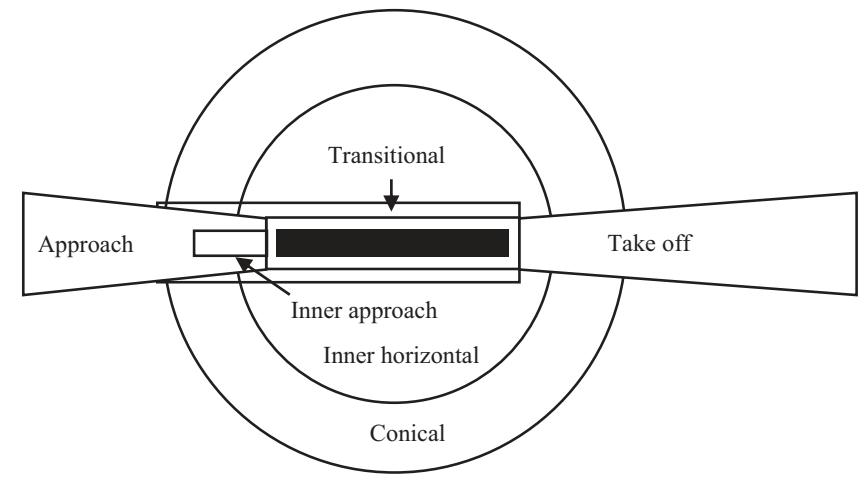

Figure 1. Obstacle limitation surfaces (OLS). Source: ICAO annex 14 (2005b).

Table 2.

Risk tolerability matrix. Source: ICAO, 2012.

\begin{tabular}{lccccc}
\hline & \multicolumn{4}{c}{ Probability of Occurrence } \\
\cline { 2 - 6 } Severity & Extremely Improbable & Extremely Remote & Remote & Reasonably Probable & Frequent \\
\hline Catastrophic & Review & Unacceptable & Unacceptable & Unacceptable & Unacceptable \\
Hazardous & Review & Review & Unacceptable & Unacceptable & Unacceptable \\
Major & Acceptable & Review & Review & Review & Review \\
Minor & Acceptable & Acceptable & Acceptable & Acceptable & Review \\
\hline
\end{tabular}

approaching a runway. The severity and frequency of these two situations are not equivalent.

According to ICAO, the accepted probability of this kind of incident to occur during an aircraft operation is defined as the acceptable safety level (ASL). This kind of approach to safety management recognizes that it is unrealistic to expect a zero risk. Some risk may have to be tolerated to secure the benefits of an activity. Risks must therefore be balanced with the benefits, with regard to the practicability of achieving further risk reduction (Eddowes et al., 2001). Assigning an ASL value to a safety standard that protects a specific phase of an aircraft operation is a complicated process since it depends on the likelihood and severity of an incident that could occur during that phase of operation. For example, the acceptable probability of a low speed aircraft wingtip collision with an object during a taxiing operation can be higher than for a catastrophic event such as an aircraft hitting an obstacle when on final approach.

According to ICAO (2012), the consequence or severity of an incident is classified into four categories: Catastrophic, Hazard, Major, and Minor. The likelihood of occurrence is categorized into Extremely Improbable, Extremely Remote, Remote, Reasonably Probable, and Frequent. The combination of those categories creates a Risk Tolerability Matrix such as the one shown in Table 2. As can be seen in Table 2, only acceptable and review incidents are allowed to occur at airports and ASL values for those incidents should be established after a cost-benefit analysis.

In this study, the event of an aircraft hitting an object on the ground when approaching or departing from a runway will be considered an extremely improbable, catastrophic event. The main objective of the OLS is to reduce the frequency of such an event as far as reasonably practicable. According to the risk tolerability matrix, the acceptable frequency of such an incident can be estimated by costbenefit analysis. According to ICAO's obstacle clearance panel, a $10^{-7}$ probability is used for risk of collision per movement with an obstacle due to the aircraft being laterally off-path or beneath the approach path (Eddowes et al., 2001). The TLS value that should be used in aeronautical studies is set by ICAO (1980; 2005b). However, this value can change from country to country or even region to region because the results of the costbenefit analysis depend on the investment made on safety in those countries. The estimation of the acceptable safety level for obstacle limitation surfaces is beyond the scope of this study. Therefore, we have assumed a $10^{-7}$ collision risk per approach as the acceptable safety value to estimate the dimensions of OLS recommended by ICAO and its obstacle clearance panel (Eddowes et al., 2001). This value was used in most recent aeronautical studies as a TLS value (Hall et al., 2008; Wong, Pitfield, Caves, \& Appleyard, 2009a). However, the proposed methodology can be used to estimate the dimensions for any given value of ASL.

Deviations from Annex 14 standards can be accepted after an aeronautical study. The primary objective of an aeronautical study is to assess the adequacy of protection provided by the existing layout for the operation of the critical aircraft (ICAO, 2005a). Therefore, it depends on several factors such as weather, geographical characteristics, aircraft operational characteristics, and the flight 
phase. Decision makers must consider those factors when they are conducting an aeronautical study in order to make modifications to the existing standards. In most of the previous studies (Wong et al., 2009a:Valdés, María, Comendador, Gordún, \& Nieto, 2011; Wong, Pitfield, Caves, \& Appleyard, 2009b), quantitative risk assessment method was used to carry out the aeronautical studies based on acceptable or target level of safety.

Quantitative risk assessment criteria were used to measure the level of safety of design standards by Eddowes and colleagues (2001) in Norwegian airports. That study identifies the need for changes in Annex 14 standards to maintain an adequate level of safety in Norwegian airports. The study also indicates that aerodrome standards can vary with respect to the geographical location of an airport. In 2010, a study was conducted by ICAO and the FAA to assess the risk level of existing OFZ standards when operating the new large aircraft (NLA) (ICAO, 2005b). OFZ is a type of OLS that provides protection for balked landings and missed approaches. The objective of that study was to verify the possibility of operating Code F aircraft in existing aerodromes that currently operate as Code E. The study used simulation flight path data to analyze the risk level of the OFZ. As a conclusion, it was shown that Code E autopilot OFZ surfaces are acceptable for autopilot operations of NLA. Furthermore, it was found that NLA that operate using a flight director (FD) can operate at Code E Category I runways. From these findings, it can be argued that the current standards for OLS were not estimated properly. Therefore, further studies will be helpful to estimate the optimal balance between safety and cost-effectiveness for OLS standards.

\section{Methodology}

The assessment of risk associated with aircraft deviation from the standard path during airborne operations is somewhat more complex than the case with ground operations, because of the three-dimensional nature of flight paths. The analysis needs to be carried out by considering all three directions that affect the deviation probability (i.e., lateral, vertical, and longitudinal). To achieve this, the proposed methodology was divided into two major components: data processing and analysis. These two components are described in detail in following sections.

\section{Flight Trajectory Data Collection and Treatment}

Flight trajectory data were collected using NAVTRACK software. NAVTRACK is a web-based application developed by Nav Canada-the air traffic service provider in Canada-capable of collecting and saving the flight path

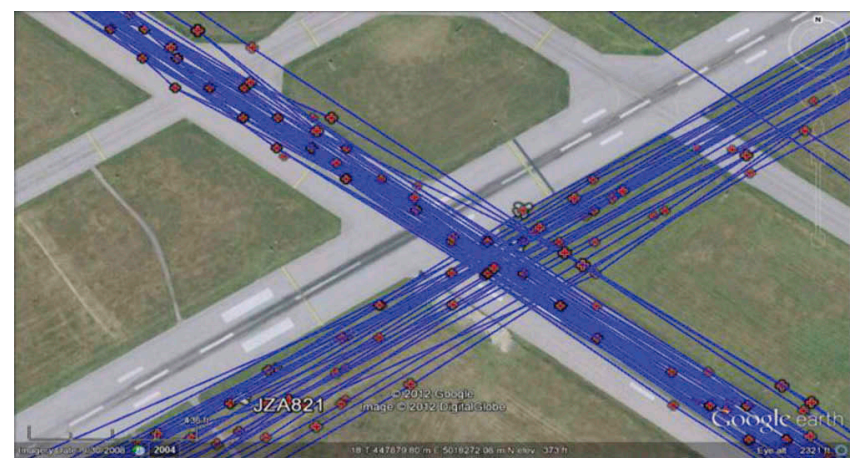

Figure 2. Observed error of flight paths.

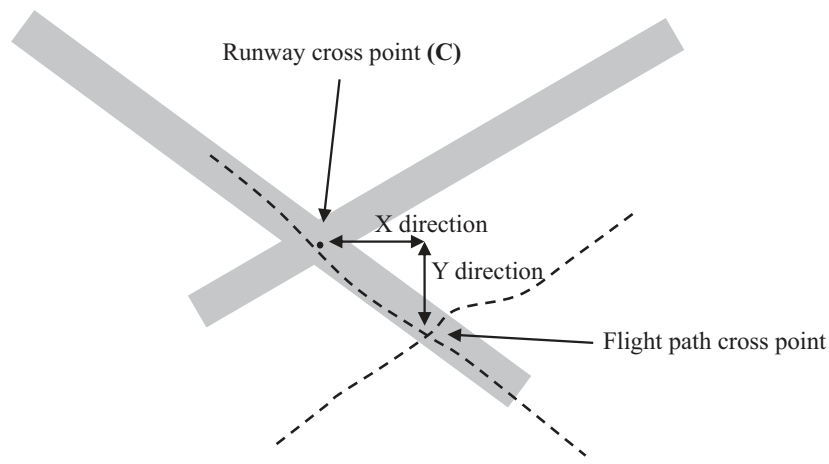

Figure 3. Runway cross point and flight path cross point. 
data that is tracked by air traffic control (ATC) secondary radars in real time. However, the positional accuracy and more information on the secondary radar system were not made available to the authors. In this study, NAVTRACK was used to collect data from August 2011 to August 2012. NAVTRACK collects the aircraft location data recorded every five seconds, within a $20 \mathrm{~km}$ radius from an airport. This information can be used to display the airplane movements on Google Earth in real time. With this data, it is possible to plot the aircraft trajectories both on take-off and final approach.

At five-second intervals, aircraft geographical position (i.e., latitude, longitude, and altitude), speed, type, ID, and origin and destination airports are tracked and saved in KMZ format (Google Earth file). These files can be directly downloaded from the server and used to view the historical flight paths in Google Earth. This option helps the user to identify the runway that was used for an aircraft operation.

The KMZ files can only be used to work with Google Earth applications. Therefore, KMZ files were converted to KML files in order to extract required information. MATLAB is a popular tool capable of reading the data in KML files. A MATLAB program was developed in order to filter the relevant information such as coordinates and aircraft attributes from the KML files. Furthermore, a separate program was developed to convert the geographical coordinate system data to the Universal Transverse Mercator (UTM) coordinate system. This conversion will help to plot the aircraft trajectories in a three-dimensional Cartesian coordinate system. The conversion equations can be found in Synder (1987).

\section{Truncation Error}

In the data filtering process, it was observed that flight paths are shifted to a southeast direction from the runway when it was plotted on Google Earth (Figure 2). According to Nav Canada, this deviation is due to the reduced number of decimal points of tracked coordinates of aircraft. Therefore, it is a constant error in the tracked coordinates and needs to be corrected before the analysis of aircraft deviation. The following methodology was used to remove that truncation error from the data. It is mainly based on the assumption that on average, aircraft should be on the runway center line when they are moving on the runway. In other words, if an airport has crossing runways, then the aircraft movements on runways should intersect at the cross point of the two runways. Therefore, this methodology can be used only at airports that have crossing runways in order to remove that truncation error from the data.

Initially, the data samples of flight paths were collected and plotted on an XY coordinate system, and coordinates of cross section points of flight paths were calculated using Cartesian geometry (Figure 5). According to the assumption, calculated cross points should be at the intersection of the two runways if there is no truncation error in the data. Therefore, the deviated distance of $\mathrm{X}$ and $\mathrm{Y}$ directions were calculated with respect to the point $\mathrm{C}$ (Figure 3 ). Then, the average deviation was calculated for both $\mathrm{X}$ and $\mathrm{Y}$ directions. This process was performed on the large and small aircraft samples (i.e., Code $1,2,3$, and 4) in order to represent the all aircraft types, and average values of deviation were calculated. According to the results, it was found that $\mathrm{X}$ and $\mathrm{Y}$ directions have $64 \mathrm{~m}$ and $-36 \mathrm{~m}$ average errors, respectively. Therefore, $64 \mathrm{~m}$ was subtracted from every coordinate in the X direction and $36 \mathrm{~m}$ was added in the $\mathrm{Y}$ direction to remove the truncation error from the data. After this correction, all the aircraft paths were on the runway and their deviation can be calculated with reference to the runway center line direction.

\section{Coordinate System}

To measure the deviation of a flight from its intended path, the coordinate system was defined with reference to the runway threshold. The origin was established at one of the runway thresholds of a given runway and the line connecting the two runway thresholds taken as the $\mathrm{Y}$ axis. The $\mathrm{X}$ axis and $\mathrm{Z}$ axis were defined as parallel to the runway surface and perpendicular to the XY plane respectively. Figure 4 shows the diagram of the coordinate system that was used in this study.

\section{Intended Flight Path}

When aircraft is on the final approach to an airport, it needs to follow a predefined path, which in this study is referred to as the intended flight path. In instrument landing system (ILS) approaches, the intended flight path is defined by the intersection between the localizer and the glide slope planes (Figure 4). In non-precision and visual approaches, aircraft should follow the extended runway center line direction, and the descent rate which is stated in approach procedures. Therefore, in non-precision approaches and visual approaches, it is difficult to find the vertical angle of the approach path because it can change with respect to point at which it starts the final approach. Therefore, it was decided to measure the vertical deviation of aircraft with respect to the runway threshold elevation and lateral deviation with respect to the runway center line.

\section{Categorization of Aircraft Approaches}

Deviation of an aircraft from its intended path could be a result of one or multiple factors. For example, it can be due to lack of pilot experience, bad weather conditions such as high cross winds and poor visibility, calibration errors of the navigation instruments that are used for instrument approaches in airports and aircraft, and so forth. As a result, it is impossible to identify the exact reason for the deviation of an aircraft when the only data available is the actual trajectories for the analysis. 

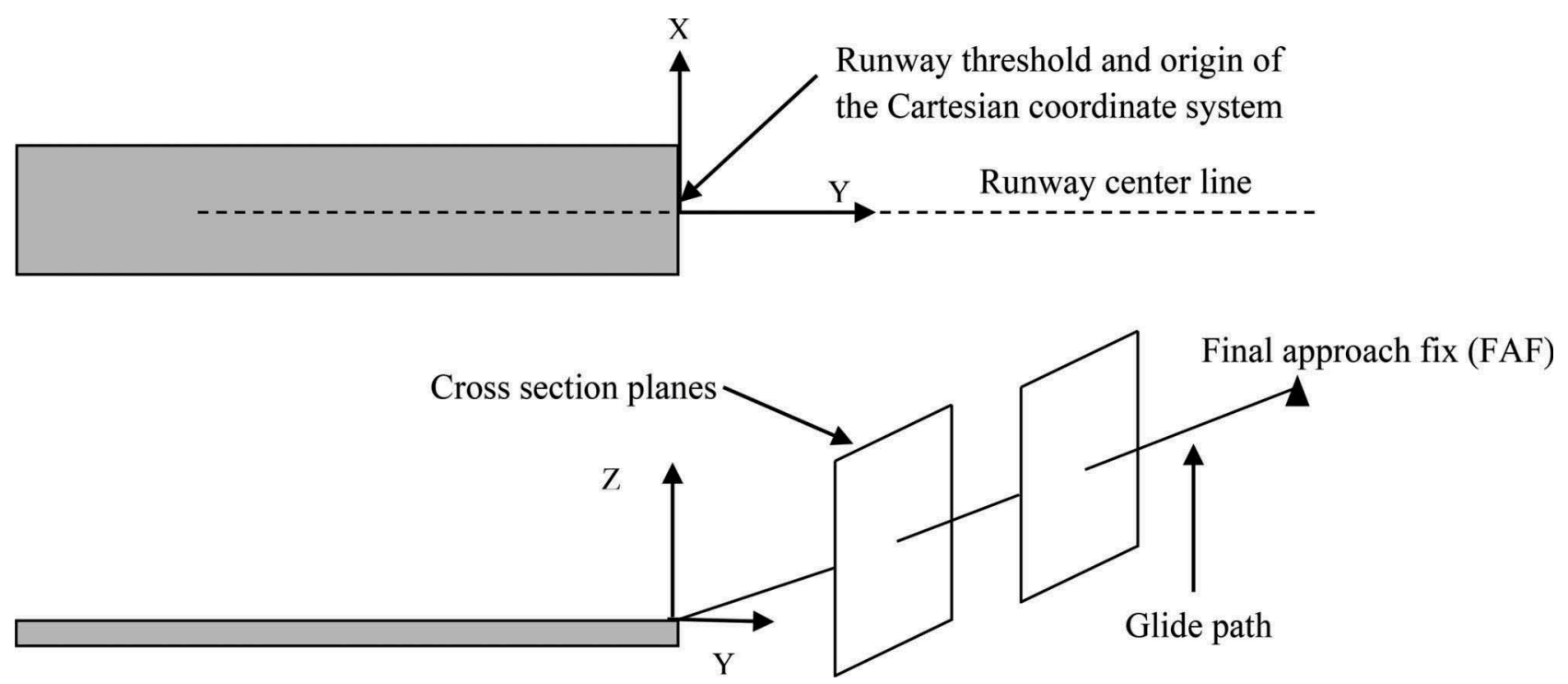

Figure 4. Runway coordinate system and intended path.

According to ICAO (1999), the effect of some of those factors on OLS dimensions is represented by categorizing the runways with respect to the approach type and code number (Table 1).

In this analysis, approach trajectory data of ICAO Code 3 aircraft on CYOW runway 07-25 were analyzed. According to the Canada air pilot (CAP) 4 document (Nav Canada, 2012), runway 07-25 has been used for both non-precision and precision approach procedures (Table 3) (Nav Canada, 2012). In precision approaches (PA), the pilot get both vertical and lateral guidance, but in nonprecision approaches (NPA), they only get lateral guidance. Therefore, if we are going to estimate OLS dimensions with respect to the type of approach (i.e., precision, nonprecision, visual), deviation data needs to be divided according to that. In order to do that categorization, a database that contains aircraft approach information for CYOW is required. However, during our study, we were unable to acquire such database for CYOW.

Therefore, it was decided to combine the non-precision and precision approach data and analyze the aircraft approaches with respect to the meteorological condition (i.e., instrument and visual) at the airport. Due to that categorization, the study is unable to show the effect of guidance system to deviations from the intended path. However, OLS is a permanent surface for a runway. Therefore, if a runway has been used for both types of approaches, then that runway's OLS should provide protection for both types of approaches. As a result, it can be argued that the dimensions of OLS that we get from this analysis by combining the NPA and PA will provide the adequate level of safety for both types of instrument approaches.

To distinguish the approaches under visual meteorological conditions (VMC) and instrument meteorological conditions (IMC), METAR data containing weather information for CYOW was obtained from the Ontario Centre for Climate Impacts and Adaptation Resources. According to Horonjeff and colleagues (2010), aircraft should use instrument procedures in IMC. However, in VMC, aircraft are allowed to use instrument approach procedures. Therefore, when we categorize the data according to the meteorological condition, instrument approach data may be included in the VMC data.

\section{Calculation of the Deviations From Intended Path}

Aircraft deviation from its protected path was calculated at $500 \mathrm{~m}$ intervals along the runway center line (Figure 4). In this calculation, it is assumed that magnitude of deviation does not change significantly within a given $500 \mathrm{~m}$ interval along the intended flight path. In this study, Cartesian geometry calculations were used to estimate the deviation distances along the extended runway center line direction. As a first step, the Cartesian equation of the runway center line was calculated using the coordinates of the runway thresholds.

$$
\mathrm{y}=\mathrm{m}_{1} \mathrm{x}+\mathrm{C}_{1}
$$

Where

$$
\begin{gathered}
\mathrm{m}_{1}=\frac{\mathrm{Y}_{1}-\mathrm{Y}_{2}}{\mathrm{X}_{1}-\mathrm{X}_{2}} ; \\
\mathrm{C}_{1}=\mathrm{Y}_{1}-\frac{\left(\mathrm{Y}_{1}-\mathrm{Y}_{2}\right) \cdot \mathrm{X}_{1}}{\left(\mathrm{X}_{1}-\mathrm{X}_{2}\right)}
\end{gathered}
$$

The equations for the cross section lines that are perpendicular to the runway center line and at 500-m intervals are

$$
\mathrm{y}=\mathrm{m}_{2} \mathrm{x}+\mathrm{C}_{2}
$$


Where

$$
\mathrm{C}_{2}=\mathrm{Y}_{1}-\mathrm{m}_{2} \mathrm{X}_{1} ; \quad \mathrm{m}_{2}=\left(1 / \mathrm{m}_{1}\right) \times(-1)
$$

and

$$
\mathrm{y}=\mathrm{m}_{3} \mathrm{x}+\mathrm{C}_{\mathrm{L}}
$$

where

$$
\mathrm{m}_{3}=\mathrm{m}_{2} ; \quad \mathrm{C}_{\mathrm{L}}=\mathrm{C}_{1}+\frac{\mathrm{L}}{\cos \theta} ; \quad \theta=\tan ^{-1}\left(\mathrm{~m}_{2}\right)
$$

Then, the equation between two tracking points of aircraft was computed as

$$
y=\mathrm{m}_{\mathrm{p}} x+\mathrm{C}_{\mathrm{p}}
$$

where

$$
\mathrm{m}_{\mathrm{p}}=\frac{\mathrm{y}_{1}-\mathrm{y}_{2}}{\mathrm{x}_{1}-\mathrm{x}_{2}} ; \quad \mathrm{C}_{\mathrm{p}}=\mathrm{y}_{1}-\frac{\left(\mathrm{y}_{1}-\mathrm{y}_{2}\right) \cdot \mathrm{x}_{1}}{\left(\mathrm{x}_{1}-\mathrm{x}_{2}\right)}
$$

In this step, we assumed that the flight path between two tracking points can be represented using a straight line. Finally, the intersection point of cross section line and flight path line was calculated.

$$
\begin{gathered}
y=\frac{C_{L} m_{p}-C_{p} m_{2}}{m_{p}-m_{2}} \\
x=\frac{C_{L}-C_{p}}{m_{p}-m_{2}}
\end{gathered}
$$

Vertical deviation $=\mathrm{z}=\mathrm{z}_{1}$

$$
-\left(\mathrm{z}_{1}-\mathrm{z}_{2}\right) \frac{\left\{\left(\mathrm{x}_{1}-\mathrm{x}_{2}\right)^{2}+\left(\mathrm{y}_{1}-\mathrm{y}_{2}\right)^{2}\right\}^{0.5}}{\left\{\left(\mathrm{x}_{1}-\mathrm{x}\right)^{2}+\left(\mathrm{y}_{1}-\mathrm{y}\right)^{2}\right\}^{0.5}}
$$

Lateral deviation $(D)=\left[\left(\mathrm{X}_{\mathrm{c}}-\mathrm{x}\right)^{2}+\left(\mathrm{Y}_{\mathrm{c}}-\mathrm{y}\right)^{2}\right]^{0.5} \quad(E q .8)$

$\left(\mathrm{x}_{\mathrm{i}}, \mathrm{y}_{\mathrm{i}}, \mathrm{z}_{\mathrm{i}}\right)=$ Tracking point coordinates of the aircraft $(\mathrm{i}=1,2)$

$\left(X_{i}, Y_{i}\right)=$ Runway threshold coordinates $(i=1,2)$

$\left(\mathrm{X}_{\mathrm{c}}, \mathrm{Y}_{\mathrm{c}}\right)=$ Runway center line and cross section line intersecting point coordinate $(\mathrm{c}=1-16)$.

$\mathrm{D}=$ deviation distance

$\mathrm{m}_{\mathrm{i}}=$ gradient of line; $\mathrm{C}_{\mathrm{i}}=$ intercept of line

These were used to measure the distance between the aircraft's center of gravity and the runway center line extension. The diagram of a flight path and the deviations is shown in Figure 5. Both horizontal and vertical deviations from the intended path were measured at each cross section plane. Afterward, aircraft characteristics and weather condition were assigned to those points to filter the data according to required categories. 

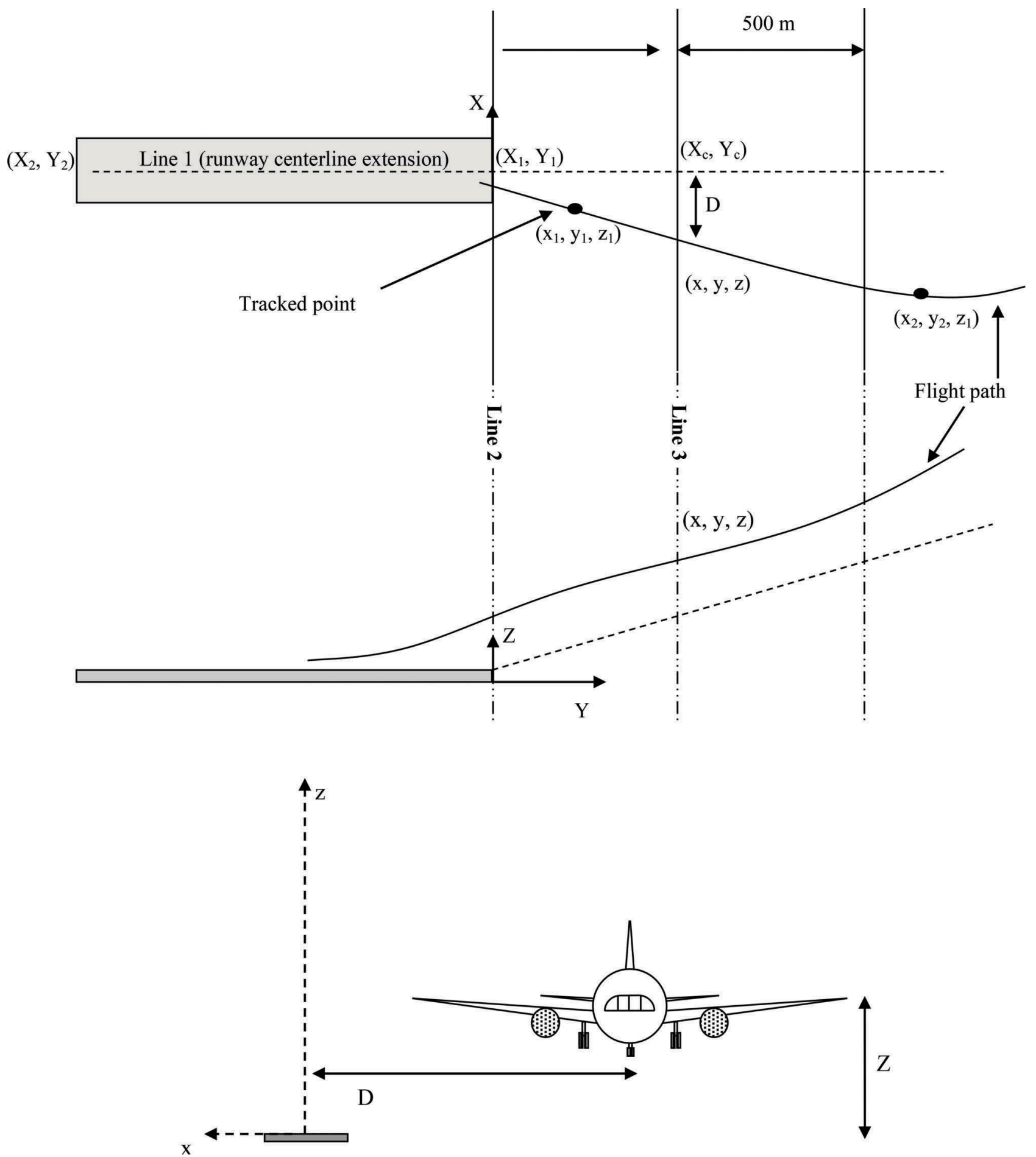

Figure 5. Notations for flight path deviation calculations.

\section{Estimation of Distribution Function Parameters}

The deviation probabilities for approaches in a cross section can be calculated by fitting the deviation data to univariate or bivariate continuous probability density functions (PDF). As described above, maximum deviation data were used for the analysis. The type and parameters of the deviation distributions need to be estimated for each $500 \mathrm{~m}$ cross section separately. Moreover, it is important to check the dependency of the lateral and vertical deviation data before estimating the distribution functions. If the data are dependent, it is necessary to estimate the joint probability functions, whereas if they are independent, two separate distribution functions can be used for the vertical and lateral deviations.

According to the above methodology, independent data were fitted to the normal mixture distribution and 
dependent data were fitted to joint normal distribution (Equations 12 and 13). The main objective of using the normal mixture distribution is obtaining a good fit not only for the tail of the distribution, but also for the central part of the distribution. However, it can be argued that the results which are produced using the normal distribution is not precise when estimating the extreme probability values such as $10^{-7}$. Therefore, in the future research, results needs to be compared with results obtained from using the extreme value distribution.

$$
\begin{aligned}
f(x)=W_{1} * f\left(x, \mu_{1}, \sigma_{1}\right) & +W_{2} * f\left(x, \mu_{2}, \sigma_{2}\right) \\
& +W_{3} * f\left(x, \mu_{3}, \sigma_{3}\right)
\end{aligned}
$$

where

$$
f\left(x, \mu_{i}, \sigma_{i}\right)=\frac{1}{\sigma \sqrt{2 \pi}} \exp \left(-\frac{\left(x-\mu_{i}\right)^{2}}{2 \sigma_{i}^{2}}\right)
$$

$$
\begin{aligned}
& f_{X, Y}(x, y)=\frac{1}{2 \pi \sigma_{1} \sigma_{2} \sqrt{\left(1-\rho^{2}\right)}} \\
& \quad \exp \left[-\frac{1}{2\left(1-\rho^{2}\right)}\left\{\left(\frac{x-\mu_{1}}{\sigma_{1}}\right)^{2}-2 \rho\left(\frac{x-\mu_{1}}{\sigma_{1}}\right)\left(\frac{y-\mu_{2}}{\sigma_{2}}\right)+\left(\frac{y-\mu_{2}}{\sigma_{2}}\right)^{2}\right\}\right]
\end{aligned}
$$

$$
\sigma_{1}>0, \sigma_{2}>0-1 \leq \rho \leq 1
$$

$\mathrm{W}_{\mathrm{i}}=$ weights

$\mu_{\mathrm{i}}=$ mean of the variable

$\sigma_{\mathrm{i}}=$ variance of the variable

$\rho=$ correlation parameter

$\mathrm{x}_{\mathrm{i}}, \mathrm{y}_{\mathrm{i}}=$ aircraft deviation (lateral or vertical)

The parameters of the distributions were estimated separately for deviation data at every $500 \mathrm{~m}$ cross section using the "nor1mix" package, which was built under $\mathrm{R}$ project. The package has functions to estimate parameters of the bivariate and univariate distribution parameters of normal distribution using the expectation maximization (EM) algorithm. The EM algorithm is an iterative method for finding maximum likelihood estimates of parameters in statistical models, where the model depends on unobserved latent variables (Maechler, 2013). Furthermore the Kolmogorov-Smirnov (K-S) test was used to measure the goodness of fit (GOF) of the distribution models. The K-S test does not produce good estimates for large sample sizes due to its poor assessment of fit at the tail (Eiger, Nadler, \& Spiegelman, 2013). However, it is important to note here that not only do the extreme probabilities affect the calculation of location probabilities, but also the middle

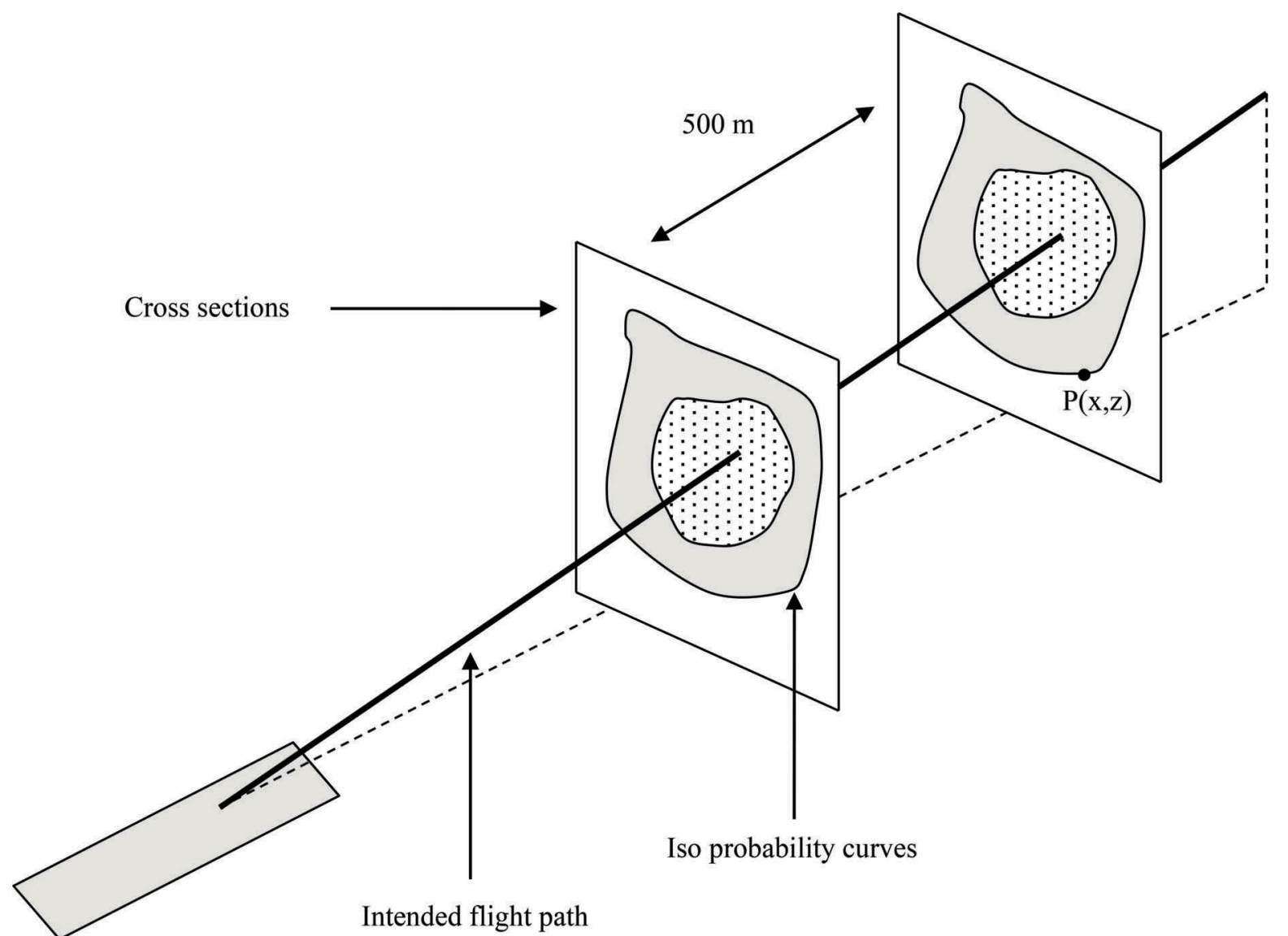

Figure 6. Iso probability curves around the intended path. 
part of the distribution. Therefore, measuring the fit in the central part of the distribution curves is also essential. For this reason, the normal mixture distribution was used to estimate the overall goodness of fit for the entire data range, and the K-S test was used to assess the fit. However, in future studies, it is recommended that an extreme value distribution be used to more accurately estimate the density function's tail.

\section{Estimation of the Required Dimensions of the Approach Surface}

As described in Section 1, the main objective of the OLS is to protect airborne aircraft from obstacles on the ground in the vicinity of an airport and reduce the likelihood of collisions with such obstacles. Therefore, the dimensions of the OLS depend on the probability of an aircraft deviating from the approach path. The OLS is defined by the surface beyond which the probability of collision with an obstacle on the ground is below the acceptable safety level.

The estimated distribution functions can be used to find the inverse of the cumulative probabilities or quantile values of the probabilities that aircraft deviate beyond a given distance. In this study, those probability values are defined as the location probabilities of an aircraft. Equations 14 and 15 can be used to estimate the quantile values of the location probabilities in a given cross section. The quantile values can be estimated for $10^{-1}$ to $10^{-7}$ location probability values for each cross section. In the next step, points that have the acceptable level of safety (i.e., $10^{-7}$ ) were identified and connected to develop iso-probability curves. This was done for each cross section, and iso-probability points were connected to develop the three-dimensional approach surface (Figure 6).

Dependent data

$$
\mathrm{q}_{\mathrm{x}, \mathrm{z}}=\mathrm{F}^{-1}\left(1-\mathrm{F}_{\mathrm{x}, \mathrm{z}}(\mathrm{x}, \mathrm{z})\right)
$$

Independent data

$$
\mathrm{q}_{\mathrm{x}, \mathrm{z}}=\left\{\mathrm{F}^{-1}\left(\mathrm{p}_{\mathrm{x}}\right)\right\},\left\{\mathrm{F}^{-1}\left(\mathrm{p}_{\mathrm{z}}\right)\right\}
$$

Where,

$$
1-\mathrm{F}_{\mathrm{x}, \mathrm{Z}}(\mathrm{x}, \mathrm{z})=p_{x} \times p_{z}=P
$$

$\mathrm{P}=$ acceptable level of safety or given location probability value

$\mathrm{F}(\mathrm{x}, \mathrm{z})=$ cumulative probability function

\section{Results}

In this study, two samples of 943 and 882 IMC and VMC Code 3 aircraft trajectories were analyzed, respectively. The categorized approach data were used to measure the aircraft deviation from its intended path and estimate deviation distribution functions. Before fitting this deviation data to distribution functions, a Pearson correlation test was carried out to check the independency of lateral and vertical deviation data in every cross section. The null hypothesis of the test is that the correlation coefficient is equal to zero, and the alternative hypothesis is that the correlation coefficient is not equal to zero. Therefore, if the $\mathrm{p}$ value of the test is greater than 0.05 , the null hypothesis cannot be rejected.

The results of the Pearson correlation test are shown in Table 4a-b for code 3 aircraft, which are operated under VMC and IMC. According to the analysis, no significant correlation between lateral and vertical deviation data was found. All the $\mathrm{p}$ values of the tests were greater than 0.05 . We cannot reject the null hypothesis at 95 confidence level. Therefore, two separate distribution functions were used for vertical and lateral deviations to calculate the deviation probability on a cross section.

Table 4a.

Pearson correlation test on data for Code 3 aircraft under IMC.

\begin{tabular}{ccc}
\hline Section & P-value & Correlation coefficient \\
\hline 500 & 0.3035 & 0.0287 \\
100 & 0.8020 & 0.0070 \\
1500 & 0.4452 & -0.0213 \\
2000 & 0.6139 & 0.0141 \\
2500 & 0.5618 & -0.0162 \\
3000 & 0.7707 & 0.0081 \\
3500 & 0.7782 & 0.0078 \\
4000 & 0.5102 & -0.0184 \\
4500 & 0.5205 & -0.0179 \\
5000 & 0.3079 & -0.0285 \\
5500 & 0.6599 & -0.0123 \\
6000 & 0.1861 & -0.0369 \\
6500 & 0.1028 & -0.0456 \\
7000 & 0.7117 & -0.0103 \\
7500 & 0.9367 & -0.0022 \\
8000 & 0.4317 & -0.0219 \\
\hline
\end{tabular}

Table $4 \mathrm{~b}$.

Pearson correlation test on data for Code 3 under VMC.

\begin{tabular}{ccc}
\hline Section & P-value & Correlation coefficient \\
\hline 500 & 0.1275 & 0.0652 \\
100 & 0.8631 & -0.0026 \\
1500 & 0.0434 & 0.0309 \\
2000 & 0.2306 & -0.0183 \\
2500 & 0.6747 & 0.0064 \\
3000 & 0.2257 & -0.0185 \\
3500 & 0.1705 & -0.0276 \\
4000 & 0.0956 & -0.0255 \\
4500 & 0.7687 & 0.0045 \\
5000 & 0.9432 & -0.0010 \\
5500 & 0.6005 & 0.0080 \\
6000 & 0.1761 & 0.0207 \\
6500 & 0.8800 & -0.0023 \\
7000 & 0.6200 & -0.0075 \\
7500 & 0.7262 & 0.0053 \\
8000 & 0.9943 & 0.0001 \\
\hline
\end{tabular}


Table 5a.

Lateral deviation distribution parameters for Code 3 aircraft under IMC.

\begin{tabular}{cccccccccccc}
\hline Section & K-S dist & P-value & $\boldsymbol{\mu 1}$ & $\boldsymbol{\mu 2}$ & $\boldsymbol{\mu 3}$ & $\boldsymbol{\sigma 1}$ & $\boldsymbol{\sigma 2}$ & $\boldsymbol{\sigma 3}$ & $\mathbf{W 1}$ & $\mathbf{W 2}$ & $\mathbf{W 3}$ \\
\hline $\mathbf{5 0 0}$ & 0.0129 & 0.9820 & -4 & -0.50 & -0.22 & 269 & 1.5 & 63 & 0.34 & 0.15 & 0.50 \\
$\mathbf{1 0 0}$ & 0.0116 & 0.9949 & -29 & -2 & 27 & 329 & 214 & 467 & 0.31 & 0.29 & 0.38 \\
$\mathbf{1 5 0 0}$ & 0.0101 & 0.9994 & -26 & 2 & 31 & 353 & 286 & 452 & 0.33 & 0.28 & 0.37 \\
$\mathbf{2 0 0 0}$ & 0.0161 & 0.8939 & -19 & 6 & 32 & 434 & 342 & 538 & 0.35 & 0.29 & 0.35 \\
$\mathbf{2 5 0 0}$ & 0.0146 & 0.9458 & -19 & 9 & 41 & 495 & 302 & 518 & 0.36 & 0.32 & 0.30 \\
$\mathbf{3 0 0 0}$ & 0.0096 & 0.9997 & -21 & 8 & 38 & 527 & 293 & 573 & 0.34 & 0.29 & 0.35 \\
$\mathbf{3 5 0 0}$ & 0.0089 & 0.9999 & -20 & 20 & 43 & 507 & 355 & 868 & 0.35 & 0.30 & 0.34 \\
$\mathbf{4 0 0 0}$ & 0.0097 & 0.9997 & -14 & 15 & 48 & 725 & 606 & 708 & 0.34 & 0.28 & 0.36 \\
$\mathbf{4 5 0 0}$ & 0.0172 & 0.8422 & -17 & 19 & 51 & 673 & 519 & 643 & 0.35 & 0.31 & 0.33 \\
$\mathbf{5 0 0 0}$ & 0.0110 & 0.9977 & -18 & 18 & 49 & 840 & 487 & 892 & 0.35 & 0.26 & 0.37 \\
$\mathbf{5 5 0 0}$ & 0.0116 & 0.9949 & -19 & 22 & 65 & 795 & 523 & 6256 & 0.39 & 0.32 & 0.27 \\
$\mathbf{6 0 0 0}$ & 0.0113 & 0.9964 & -23 & 22 & 63 & 891 & 515 & 878 & 0.34 & 0.31 & 0.33 \\
$\mathbf{6 5 0 0}$ & 0.0102 & 0.9992 & -28 & 23 & 633 & 948 & 480 & 1256 & 0.38 & 0.24 & 0.37 \\
$\mathbf{7 0 0 0}$ & 0.0141 & 0.9605 & -23 & 15 & 61 & 1446 & 905 & 1395 & 0.35 & 0.26 & 0.37 \\
$\mathbf{7 5 0 0}$ & 0.0094 & 0.9998 & -31 & 22 & 68 & 1170 & 770 & 1468 & 0.34 & 0.28 & 0.36 \\
$\mathbf{8 0 0 0}$ & 0.0122 & 0.9908 & -34 & 27 & 69 & 1315 & 1150 & 1888 & 0.34 & 0.30 & 0.35 \\
\hline
\end{tabular}

Table 5b.

Vertical deviation distribution parameters Code 3 aircraft under IMC.

\begin{tabular}{cccccccccccc}
\hline Section & K-S dist & P-value & $\boldsymbol{\mu 1}$ & $\boldsymbol{\mu 2}$ & $\boldsymbol{\mu 3}$ & $\boldsymbol{\sigma 1}$ & $\boldsymbol{\sigma 2}$ & $\boldsymbol{\sigma 3}$ & $\mathbf{W 1}$ & $\mathbf{W 2}$ & $\mathbf{W 3}$ \\
\hline $\mathbf{5 0 0}$ & 0.0109 & 0.9980 & 152 & 152 & 172 & 81 & 26 & 113 & 0.27 & 0.32 & 0.40 \\
$\mathbf{1 0 0}$ & 0.0129 & 0.9825 & 183 & 184 & 208 & 157 & 46 & 53 & 0.29 & 0.53 & 0.16 \\
$\mathbf{1 5 0 0}$ & 0.0170 & 0.8529 & 204 & 213 & 235 & 161 & 50 & 87 & 0.21 & 0.62 & 0.15 \\
$\mathbf{2 0 0 0}$ & 0.0180 & 0.8003 & 222 & 243 & 265 & 75 & 49 & 80 & 0.20 & 0.69 & 0.10 \\
$\mathbf{2 5 0 0}$ & 0.0158 & 0.9060 & 252 & 274 & 274 & 74 & 36 & 246 & 0.27 & 0.42 & 0.30 \\
$\mathbf{3 0 0 0}$ & 0.0096 & 0.9997 & 279 & 304 & 301 & 54 & 44 & 267 & 0.30 & 0.43 & 0.25 \\
$\mathbf{3 5 0 0}$ & 0.0160 & 0.8949 & 307 & 333 & 329 & 49 & 45 & 215 & 0.36 & 0.34 & 0.29 \\
$\mathbf{4 0 0 0}$ & 0.0146 & 0.9468 & 338 & 351 & 364 & 54 & 350 & 49 & 0.45 & 0.18 & 0.36 \\
$\mathbf{4 5 0 0}$ & 0.0147 & 0.9433 & 361 & 367 & 389 & 136 & 33 & 117 & 0.21 & 0.28 & 0.50 \\
$\mathbf{5 0 0 0}$ & 0.0119 & 0.9928 & 391 & 397 & 421 & 192 & 37 & 100 & 0.27 & 0.33 & 0.39 \\
$\mathbf{5 5 0 0}$ & 0.0176 & 0.8187 & 400 & 425 & 445 & 52 & 66 & 151 & 0.08 & 0.45 & 0.45 \\
$\mathbf{6 0 0 0}$ & 0.0107 & 0.9984 & 433 & 458 & 483 & 55 & 77 & 66 & 0.15 & 0.62 & 0.22 \\
$\mathbf{6 5 0 0}$ & 0.0135 & 0.9731 & 463 & 486 & 498 & 76 & 51 & 142 & 0.23 & 0.36 & 0.39 \\
$\mathbf{7 0 0 0}$ & 0.0120 & 0.9923 & 493 & 512 & 533 & 99 & 88 & 132 & 0.33 & 0.30 & 0.35 \\
$\mathbf{7 5 0 0}$ & 0.0131 & 0.9803 & 528 & 548 & 556 & 232 & 47 & 197 & 0.46 & 0.25 & 0.28 \\
$\mathbf{8 0 0 0}$ & 0.0200 & 0.6818 & 556 & 578 & 588 & 197 & 43 & 127 & 0.55 & 0.17 & 0.27 \\
\hline
\end{tabular}

Table 5c.

Lateral deviation distribution parameters Code 3 aircraft under VMC.

\begin{tabular}{cccccccccccc}
\hline Section & K-S dist & P-value & $\boldsymbol{\mu 1}$ & $\boldsymbol{\mu 2}$ & $\boldsymbol{\mu 3}$ & $\boldsymbol{\sigma 1}$ & $\boldsymbol{\sigma 2}$ & $\boldsymbol{\sigma 3}$ & $\mathbf{W 1}$ & $\mathbf{W 2}$ & W3 \\
\hline $\mathbf{5 0 0}$ & 0.0086 & 0.9071 & -0.25 & -0.35 & -3.0 & 44 & 1.8 & 298 & 0.44 & 0.12 & 0.42 \\
$\mathbf{1 0 0}$ & 0.0088 & 0.8948 & -26 & 1.0 & 32 & 351 & 303 & 380 & 0.36 & 0.28 & 0.34 \\
$\mathbf{1 5 0 0}$ & 0.0080 & 0.9464 & -21 & 11 & 34 & 371 & 418 & 575 & 0.35 & 0.28 & 0.35 \\
$\mathbf{2 0 0 0}$ & 0.0072 & 0.9795 & -21 & 12 & 38 & 352 & 271 & 521 & 0.35 & 0.29 & 0.34 \\
$\mathbf{2 5 0 0}$ & 0.0068 & 0.9872 & -17 & 14 & 40 & 445 & 379 & 619 & 0.34 & 0.29 & 0.35 \\
$\mathbf{3 0 0 0}$ & 0.0053 & 0.9996 & -18 & 13 & 44 & 464 & 331 & 593 & 0.34 & 0.28 & 0.36 \\
$\mathbf{3 5 0 0}$ & 0.0079 & 0.9504 & -16 & 16 & 49 & 483 & 336 & 592 & 0.34 & 0.28 & 0.37 \\
$\mathbf{4 0 0 0}$ & 0.0056 & 0.9992 & -15 & 23 & 51 & 647 & 448 & 808 & 0.35 & 0.29 & 0.34 \\
$\mathbf{4 5 0 0}$ & 0.0078 & 0.9543 & -16 & 19 & 57 & 684 & 406 & 716 & 0.35 & 0.28 & 0.36 \\
$\mathbf{5 0 0 0}$ & 0.0067 & 0.9902 & -21 & 19 & 55 & 721 & 442 & 866 & 0.34 & 0.27 & 0.37 \\
$\mathbf{5 5 0 0}$ & 0.0087 & 0.9024 & -23 & 21 & 61 & 808 & 516 & 877 & 0.34 & 0.30 & 0.34 \\
$\mathbf{6 0 0 0}$ & 0.0067 & 0.9906 & -23 & 23 & 65 & 905 & 578 & 1037 & 0.34 & 0.30 & 0.35 \\
$\mathbf{6 5 0 0}$ & 0.0075 & 0.9693 & -27 & 21 & 65 & 880 & 623 & 1168 & 0.32 & 0.30 & 0.37 \\
$\mathbf{7 0 0 0}$ & 0.0074 & 0.9709 & -28 & 23 & 69 & 1072 & 873 & 1474 & 0.33 & 0.30 & 0.35 \\
$\mathbf{7 5 0 0}$ & 0.0078 & 0.9527 & -32 & 28 & 65 & 1032 & 1113 & 1801 & 0.33 & 0.29 & 0.37 \\
$\mathbf{8 0 0 0}$ & 0.0086 & 0.9082 & -34 & 23 & 64 & 1390 & 1187 & 2241 & 0.30 & 0.26 & 0.42 \\
\hline
\end{tabular}


Table 5d.

Vertical deviation distribution parameters Code aircraft under VMC

\begin{tabular}{cccccccccccc}
\hline Section & K-S dist & P-value & $\boldsymbol{\mu 1}$ & $\boldsymbol{\mu 2}$ & $\boldsymbol{\mu 3}$ & $\boldsymbol{\sigma 1}$ & $\boldsymbol{\sigma 2}$ & $\boldsymbol{\sigma 3}$ & W1 & W2 & W3 \\
\hline $\mathbf{5 0 0}$ & 0.0110 & 0.6690 & 152 & 153 & 170 & 158 & 32 & 149 & 0.24 & 0.3 \\
$\mathbf{1 0 0}$ & 0.0109 & 0.6890 & 180 & 183 & 194 & 193 & 34 & 186 & 0.28 & 0.37 & 0.38 \\
$\mathbf{1 5 0 0}$ & 0.0125 & 0.5158 & 192 & 213 & 223 & 74 & 39 & 220 & 0.14 & 0.57 & 0.27 \\
$\mathbf{2 0 0 0}$ & 0.0124 & 0.5212 & 221 & 243 & 248 & 71 & 39 & 268 & 0.24 & 0.49 & 0.26 \\
$\mathbf{2 5 0 0}$ & 0.0121 & 0.5554 & 248 & 272 & 276 & 50 & 51 & 313 & 0.30 & 0.48 & 0.20 \\
$\mathbf{3 0 0 0}$ & 0.0127 & 0.4951 & 277 & 302 & 298 & 49 & 54 & 436 & 0.36 & 0.42 \\
$\mathbf{3 5 0 0}$ & 0.0095 & 0.8339 & 307 & 322 & 332 & 58 & 493 & 56 & 0.43 & 0.25 \\
$\mathbf{4 0 0 0}$ & 0.0238 & 0.0153 & 314 & 335 & 355 & 76 & 35 & 261 & 0.06 & 0.32 & 0.31 \\
$\mathbf{4 5 0 0}$ & 0.0180 & 0.1243 & 344 & 365 & 383 & 59 & 42 & 294 & 0.10 & 0.31 \\
$\mathbf{5 0 0 0}$ & 0.0185 & 0.1042 & 372 & 395 & 411 & 53 & 38 & 376 & 0.12 & 0.32 & 0.57 \\
$\mathbf{5 5 0 0}$ & 0.0154 & 0.2632 & 400 & 425 & 437 & 50 & 48 & 441 & 0.13 & 0.30 \\
$\mathbf{6 0 0 0}$ & 0.0116 & 0.6112 & 432 & 456 & 465 & 64 & 40 & 502 & 0.20 & 0.25 & 0.55 \\
$\mathbf{6 5 0 0}$ & 0.0090 & 0.8759 & 461 & 487 & 493 & 63 & 67 & 689 & 0.28 & 0.31 & 0.43 \\
$\mathbf{7 0 0 0}$ & 0.0133 & 0.4352 & 488 & 502 & 521 & 26 & 355 & 763 & 0.14 & 0.42 & 0.42 \\
$\mathbf{7 5 0 0}$ & 0.0167 & 0.1827 & 513 & 543 & 564 & 210 & 421 & 1758 & 0.27 & 0.65 & 0.06 \\
$\mathbf{8 0 0 0}$ & 0.0165 & 0.1939 & 547 & 582 & 588 & 218 & 346 & 2281 & 0.51 & 0.41 & 0.07 \\
\hline
\end{tabular}

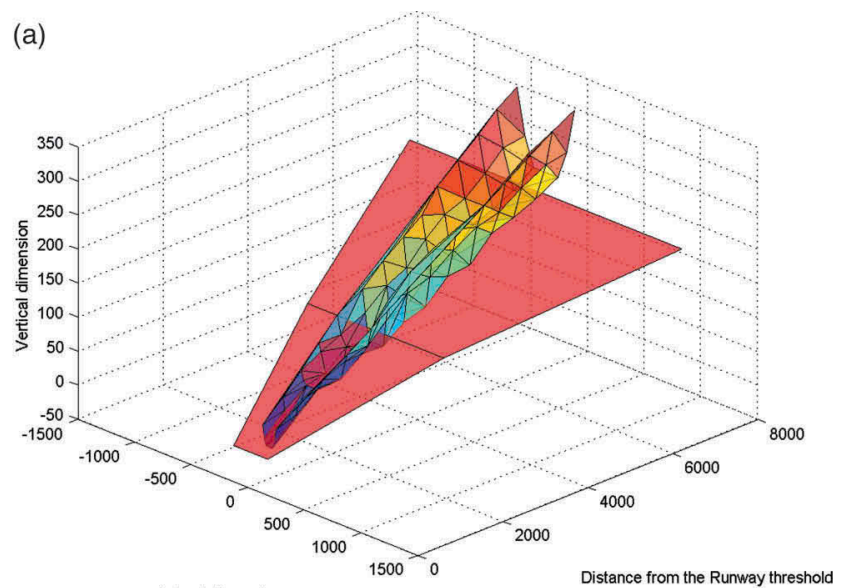

(b)

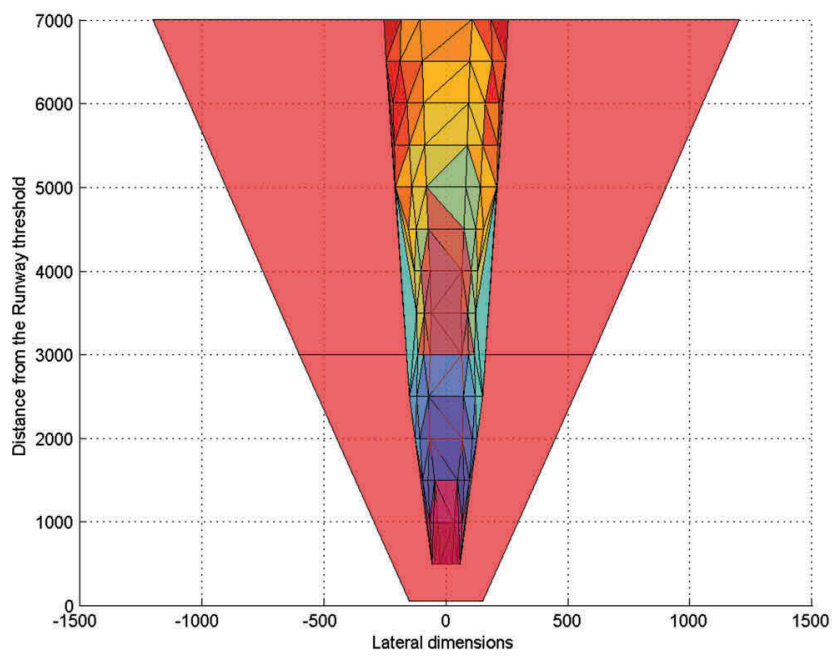

(c)

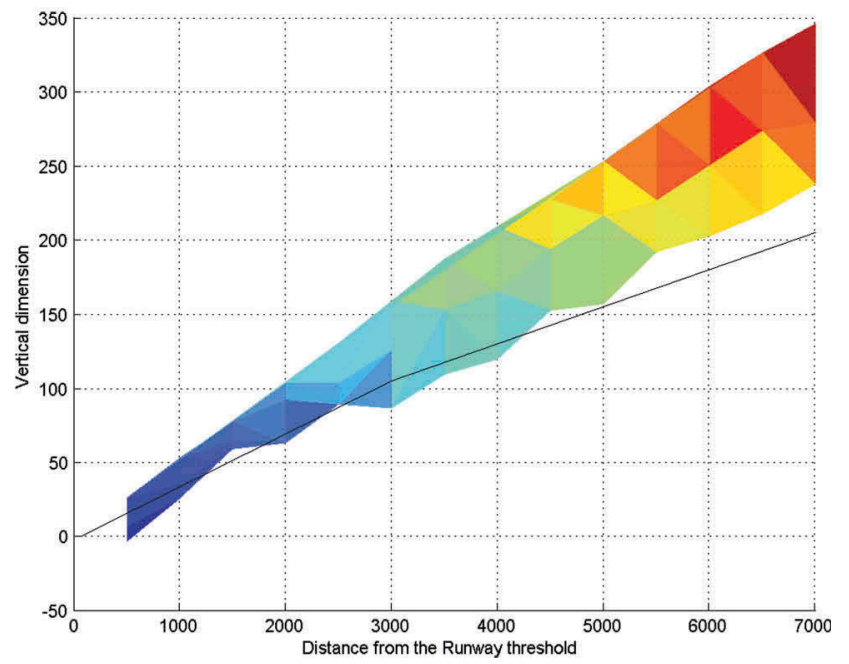

Figure 7a. 3-D view of the ${ }^{10-7}$ estimated OLS surface for Code 3 IMC aircraft approaches with existing ICAO OLS surface. Figure 7b. Plan view of the ${ }^{10-7}$ estimated OLS surface for Code 3 IMC aircraft approaches with existing ICAO OLS surface. Figure 7c. Profile view view of the ${ }^{10-7}$ estimated OLS surface for Code 3 IMC aircraft approaches with existing ICAO OLS surface. 


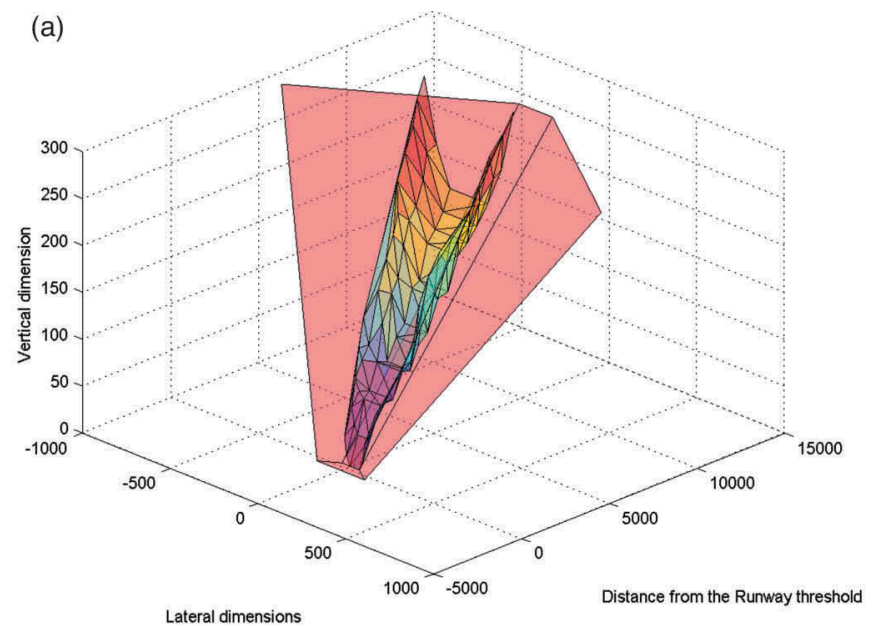

(b)

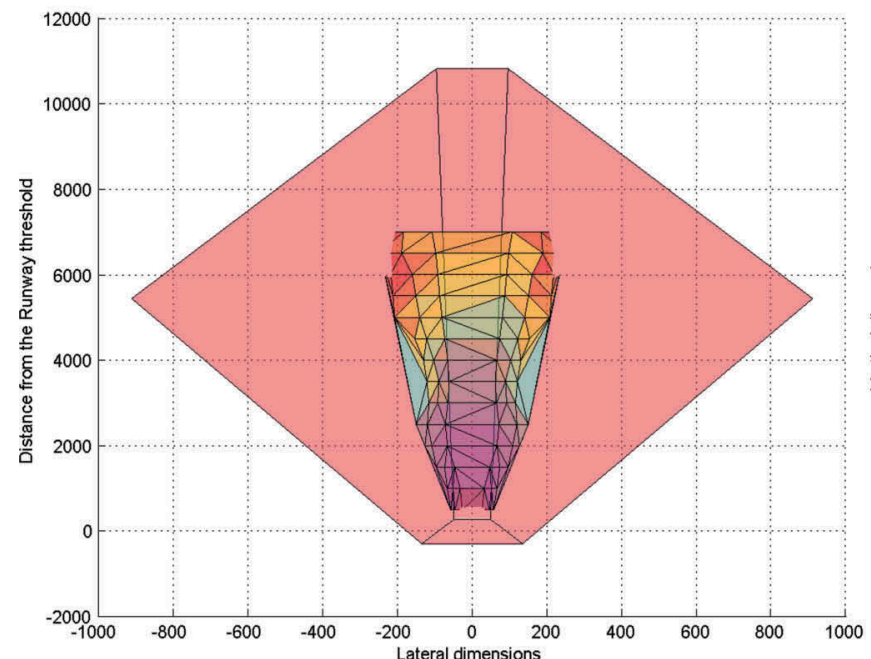

(c)

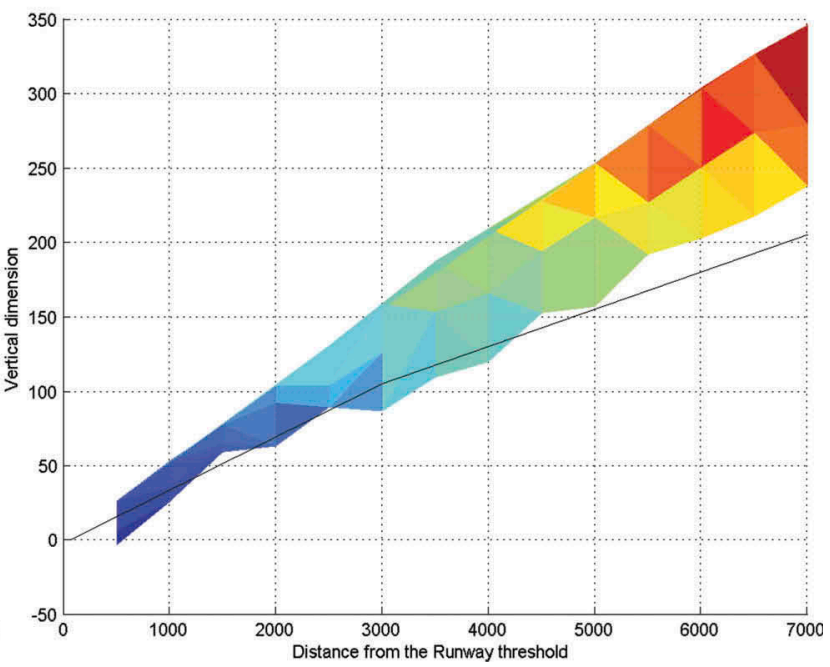

Figure 8a. 3-D view of the ${ }^{10-7}$ estimated OLS surface for Code 3 IMC aircraft approaches with existing ICAO PANS-OPS surface. Figure 8b. Plan view of the ${ }^{10-7}$ estimated OLS surface for Code 3 IMC aircraft approaches with existing ICAO OLS surface. Figure 8c. Profile view of the ${ }^{10-7}$ estimated OLS surface for Code 3 IMC aircraft approaches with existing ICAO OLS surface.

The estimated parameters of the mixture of normal distribution and K-S goodness of fit results are shown in Table 5a-d for each meteorological condition. The estimated goodness of the fit test's $\mathrm{p}$ values indicates that all the models have a significant goodness of fit.

Iso-probability surfaces for IMC approaches for a $10^{-7}$ location probability are shown with the existing ILS and PANS-OPS surfaces in Figures 7 and 8, respectively. In this study, we assumed that IMC approaches represent instrument approaches. Therefore, the estimated surface was also compared with the PANS-OPS surface, which is specifically designed to protect instrument approaches. To estimate the dimensions of the PANS-OPS surface, it was assumed that the glide path angle is $3^{\circ}$, the distance between the localizer and the runway threshold is $3,000 \mathrm{~m}$, and the missed approach gradient is $2.5 \%$. The dimensions of the assumed surface were obtained from the examples presented in the PANS-OPS standards document. Figure 9 compares the estimated surface for VMC approaches with the non-instrument surface. The plain color surfaces show the existing dimensions of the OLS/PANS-OPS, and the surfaces illustrated with multiple colors represent this study's estimated surface dimensions. The different colors of the estimated surfaces were used to show changes in the vertical dimensions and to provide a visual comparison. The estimated lateral and vertical maximum values of the surface for each cross section along the approach path are shown in Table 6a-b.

The results of the analysis show that the estimated lateral dimensions of the approach surfaces were smaller than both the Annex 14 standards and PANS-OPS standards. However, the required lateral dimensions were comparatively higher for the IMC approaches than for the VMC approaches. Moreover, the estimated surfaces indicate that 
(a)

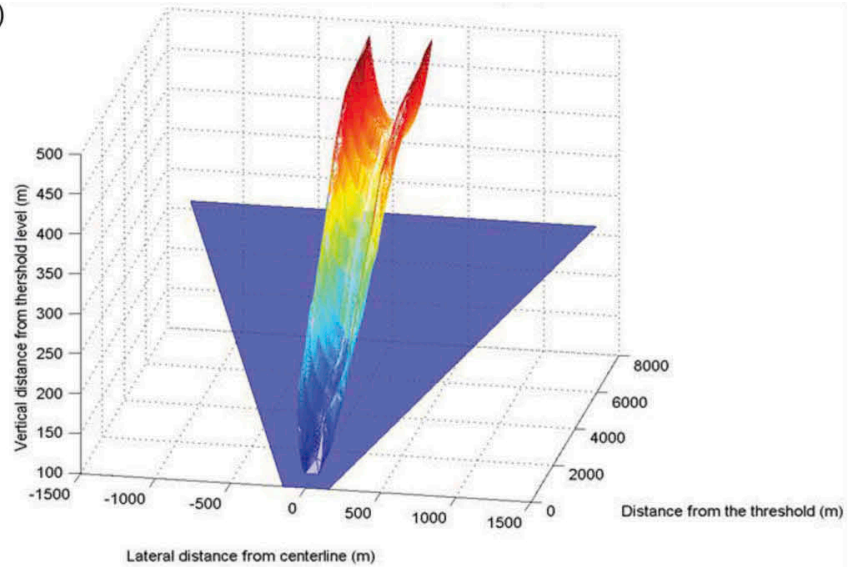

(b)

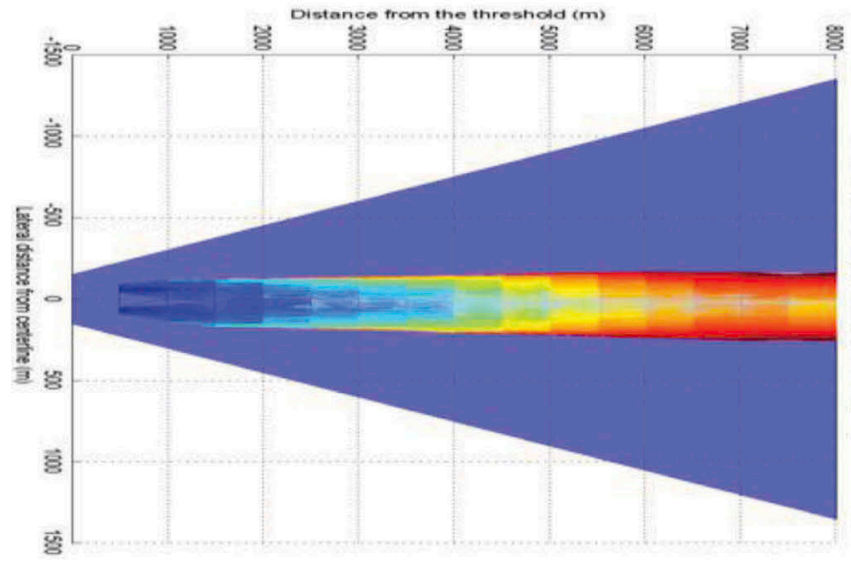

(c)

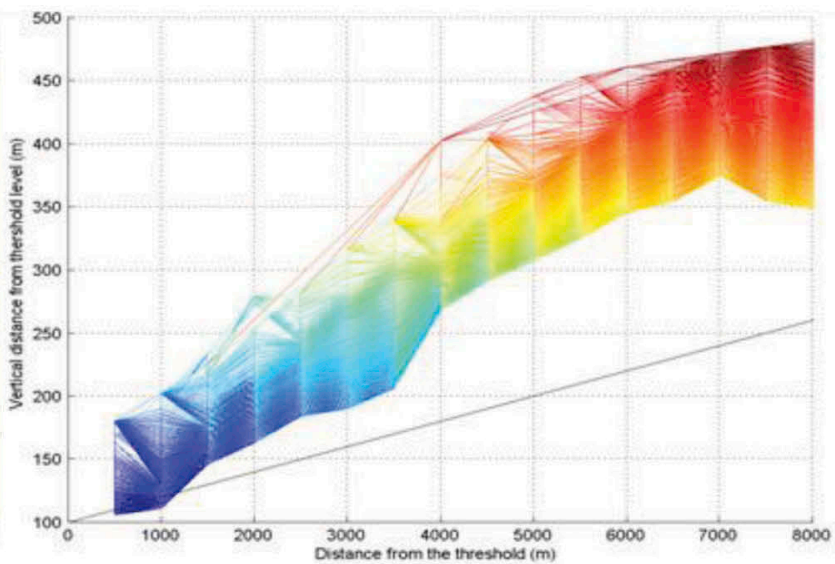

Figure 9a. 3D view of the ${ }^{10-7}$ iso-probability curve for Code 3 aircraft approaches under VMC. Figure 9b. Plan view of the ${ }^{10-7}$ iso-probability curve for Code 3 aircraft approaches under VMC. Figure 9c. Profile view of the ${ }^{10-7}$ iso-probability curve for Code 3 aircraft approaches under VMC.

vertical dimensions of some of the approach surfaces require greater clearance than the existing surfaces in IMC operations.

It can be concluded that there has been improvement in airport navigational facilities compared with the past, which has affected the magnitude of aircraft deviation from its intended path. However, these results cannot be used to assess the effect of navigational facilities between instrument and non-instrument approaches due to the absence of approach type information. Therefore, to conduct a more detailed analysis, it is important to know the type of approach for each flight trajectory.

Furthermore the developed surface's dimensions are presented without considering the effect of aircraft geometry to its dimensions. Therefore, the wingspan length and aircraft height must be taken into account when calculating the critical OLS dimensions for an airport. As a result, aircraft types that are operated at an airport also significantly affect the OLS dimensions.

\section{Conclusion}

This paper summarizes the methodology that was used to calculate the probability of aircraft deviations from their intended path. Deviation probability functions were developed using the collected aircraft approach trajectories at CYOW. The data were extracted from the NAVTRACK software developed by Nav Canada. This study proposes a novel approach to assess the risk of OLS using actual flight path data. Most of the previous studies related to the obstacle restriction standards were developed using simulated flight paths. Those studies are not capable to represent all the factors in aircraft deviation. It is obvious that we cannot also identify all of those influence factors. However, those factors are embedded in the actual deviations measured. The same methodology can be used to develop the probability models for missed approaches and take off operations to estimate the dimensions of the take off and transitional surfaces. 


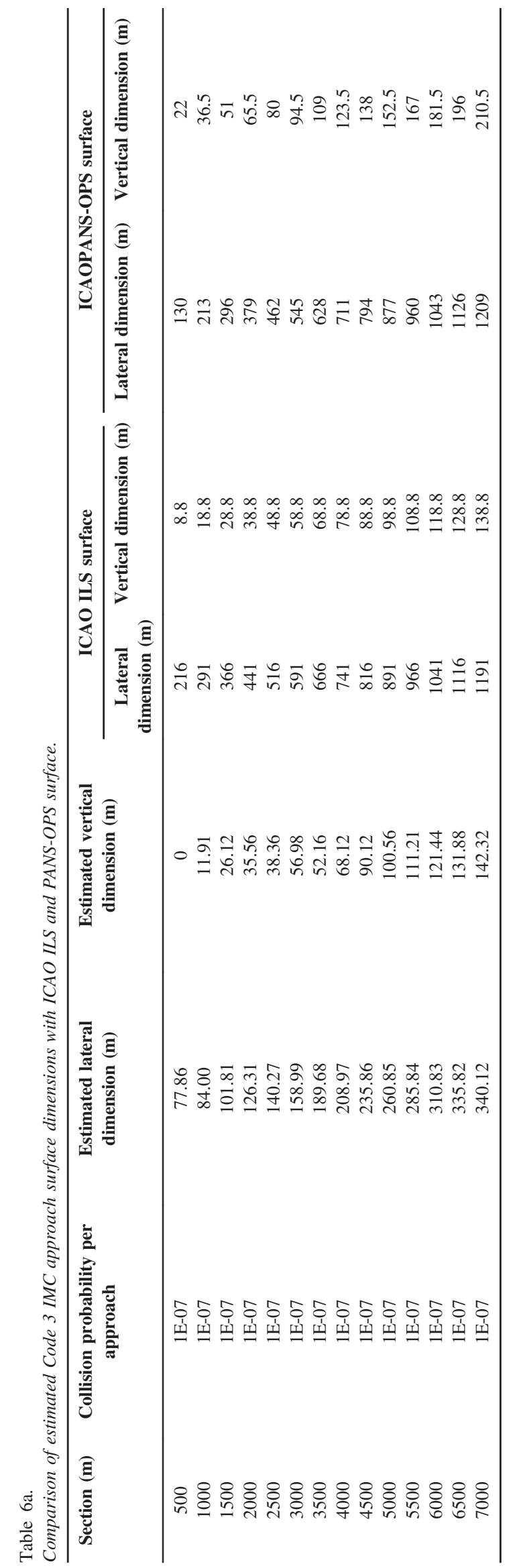


Table 6b.

Comparison of estimated Code 3 VMC approach surface dimensions with ICAO non-instrument surface.

\begin{tabular}{|c|c|c|c|c|c|}
\hline \multirow[t]{2}{*}{ Section (m) } & \multirow{2}{*}{$\begin{array}{c}\text { Collision } \\
\text { probability per } \\
\text { approach }\end{array}$} & \multirow{2}{*}{$\begin{array}{l}\text { Estimated lateral } \\
\text { dimension }(\mathbf{m})\end{array}$} & \multirow{2}{*}{$\begin{array}{l}\text { Estimated vertical } \\
\text { dimension }(\mathbf{m})\end{array}$} & \multicolumn{2}{|c|}{ ICAO ILS surface } \\
\hline & & & & Lateral dimension (m) & Vertical dimension (m) \\
\hline 500 & $1 \mathrm{E}-07$ & 97.81 & 12.15 & 119 & 14.652 \\
\hline 1000 & $1 \mathrm{E}-07$ & 99.49 & 50.57 & 169 & 31.302 \\
\hline 1500 & $1 \mathrm{E}-07$ & 90.33 & 150.36 & 219 & 47.952 \\
\hline 2000 & $1 \mathrm{E}-07$ & 95.23 & 160.23 & 269 & 64.602 \\
\hline 2500 & $1 \mathrm{E}-07$ & 126.18 & 180.63 & 319 & 81.252 \\
\hline 3000 & $1 \mathrm{E}-07$ & 135.50 & 185.26 & 369 & 97.902 \\
\hline 3500 & $1 \mathrm{E}-07$ & 134.90 & 226.23 & 419 & 114.552 \\
\hline 4000 & $1 \mathrm{E}-07$ & 142.98 & 270.56 & 469 & 131.202 \\
\hline 4500 & $1 \mathrm{E}-07$ & 152.78 & 280.12 & 519 & 147.852 \\
\hline 5000 & $1 \mathrm{E}-07$ & 162.08 & 312.86 & 569 & 164.502 \\
\hline 5500 & $1 \mathrm{E}-07$ & 155.03 & 324.23 & 619 & 181.152 \\
\hline 6000 & $1 \mathrm{E}-07$ & 160.35 & 338.89 & 669 & 197.802 \\
\hline 6500 & $1 \mathrm{E}-07$ & 180.17 & 353.55 & 719 & 214.452 \\
\hline 7000 & $1 \mathrm{E}-07$ & 199.98 & 368.21 & 769 & 231.102 \\
\hline 7500 & $1 \mathrm{E}-07$ & 219.80 & 356.19 & 819 & 247.752 \\
\hline 8000 & $1 \mathrm{E}-07$ & 239.61 & 350.14 & 869 & 264.402 \\
\hline
\end{tabular}

The results of this study indicate that there is a considerable difference between dimensions of the existing ICAO ILS and PANS-OPS approach surface, and estimated surfaces that were obtained using the observed flight paths. This shows that the dimensions of existing surfaces may be overestimated as they provide higher levels of safety for aircraft operations than prescribed by ICAO. This is a desirable result at airport sites where the OLS impose no significant restrictions either to aircraft operations or to the land use in the airport's vicinity. However, if there is a restriction to aircraft operations at an airport due to obstacles that penetrate the OLS or PANS-OPS surface prescribed by the standards, this methodology can be used to check the level of safety of those operations or the risk of collisions with said obstacles. Furthermore, the goodness of fit test results indicate that models can produce statistically significant results, which is a good encouragement for future works stemming from this study. The proposed methodology will be a great help for airport expansion projects because airport owners will able to manage their available space efficiently by assessing the level of safety of aircraft operations. Using the proposed methodology, the risk of collision with objects around the airports can be calculated. This will also be helpful for real estate developers to identify the limitations of their constructions, such as the height of the buildings. Moreover, this methodology can be used in the future to develop a computer model to estimate the risk level imposed by obstacles around the airports for both visual and instrument aircraft approaches.

The results of the study are based on the data collected from CYOW runway 07-25. For other runways and other airports, separate analyses need to be performed for different approach types to the same runway to estimate the critical surface that should be used as the OLS. Moreover, other runways in CYOW and other airports need to be modeled to observe the effect of approach types and geographical condition on aircraft deviation from intended paths. The effect of positional error of radar tracking points in the analysis results is also acknowledged. Positional errors of tracked coordinates can impact the calculations of aircraft deviation from its intended path. According to Equations 7 and 8, the magnitude of error in deviation values (i.e., $\mathrm{D}$ and $\mathrm{z}$ ) is decided by the positional accuracy of the $\mathrm{x}_{\mathrm{i}}, \mathrm{y}_{\mathrm{i}}$, and $\mathrm{z}_{\mathrm{i}}$ coordinates. Therefore, it can be argued that the parameters of the deviation distributions also are dependent upon the positional accuracy of the tracked coordinates. Nevertheless, if it were possible to collect more accurate aircraft trajectories, then the effect of positional error to the analysis would be insignificant. As a result, a methodology to model the positional error would not be required.

\section{Acknowledgments}

The authors wish to thank Nav Canada for providing the data on Ottawa International Airport and access to the NAVTRACK software. This research was partially funded by a grant from the Natural Sciences and Engineering Research Council of Canada.

\section{References}

CAA. (2011). Licensing of aerodromes (9th ed.). Norwich: UK Civil Aviation Authority.

CAASL. (2010). Safety risk assessment manual (1st ed.). Sri Lanka: Civil Aviation Authority of Sri Lanka, Colombo. 
Cramer, M., \& Rodriguez, L. (2013). Analysis of aircraft lateral path deviation, integrated communications, navigation and surveillance conference (ICNS). Herndon, VA: IEEE.

Eddowes, M., Hancox, J., \& MacInnes, A. (2001). Final report on the risk analysis in support of aerodrome design rules: Report for the Norwegian Civil Aviation Authority. Warrington, UK: AEA Technologies.

Eiger, A. M., Nadler, B., \& Spiegelman, C. (2013). The calibrated Kolmogorov-Smirnov test. Ithaca, NY: Cornell Univerity.

FAA. (2004). Airport design: Advisory circular 150/5300-13, including changes. Washington, DC: Federal Aviation Administration.

Fricke, H., \& Thiel, C. (2013). A methodology to assess the safety of aircraft operations when aerodrome obstacle standards cannot be met. Tenth USA/Europe Air Traffic Management Research and Development Seminar, Chicago, Illinois.

Hall, J., Ayres, M., Wong, D., Appleyard, A., Eddows, M., Shirazi, H.,. . . Puzin, T. (2008). ACRP report 3: Analysis of aircraft overruns and undershoots for runway safety areas. Washington, DC: Transport Research Board.

Horonjeff, R., McKelvey, F. X., Sproule, W. J., \& Young, S. B. (2010). Planning and Design of Airports. New York: McGraw-Hill.

ICAO. (1980). Doc 9274 manual on the use of the Collision Risk Model (CRM) for ILS operations (1st ed.). Montreal: International Civil Aviation Organization.

ICAO. (1983). Airport services manual Part VI: Control of obstacles (2nd ed.). Montreal: International Civil Aviation Organization.

ICAO. (1999). Aerodromes: International standards and recommended practices: Annex 14 to the Convention on International Civil Aviation (3rd ed.). Montreal: International Civil Aviation Organization.

ICAO. (2005a). Airport services manual Part II: Taxiway apron and holding bays (4th ed.). Montreal: International Civil Aviation Organization.

ICAO. (2005b). New larger airplanes: Infringement of the obstacle free zone: Operational measures and aeronautical study. Montreal: International Civil Aviation Organization.

ICAO. (2006). Procedures for Air Navigation Services ( $5^{\text {th }}$ ed.). International Civil Aviation Organization, Montreal.

ICAO. (2012). Safety management manual (SMM). Montreal: International Civil Aviation Organization.
Litesheim, S., \& Xiao, X. (2006). Airport obstacle surfaces. Journal of Advanced Transportation, 43, 347-366.

Maechler, M. (2013). Normal (1-D) mixture models (S3 classes and methods) (1.1.4 ed.). R package. [MORE INFORMATION NEEDED. WHAT KIND OF REFERENCE IS THIS?]

Marco, A. D., \& Auria, J. D. (2014). Collision risk studies with 6 dof flight simulations when aerodrome obstacle standards cannot be met. 29th Congress of the International Council of the Aeronotical Science, St. Petersburg, Russia.

MITRE. (2015). About MITRE. Retrieved from http://www.mitre.org/

Nav Canada. (2012). Canada air pilot (CAP 4) instrumental procedures Nav Canada. [MORE INFORMATION NEEDED.]

Snyder, J. P. (1987). Map projections: A working manual. Washington, DC: U.S. Geological Survey.

Thiel, C., \& Fricke, H. (2010). Collision Risk on Final ApproachA radar-data based evaluation method to assess safety. 4th International Conference on Research in Air Transportation (ICRAT), Budapest.

Thiel, C., Seiß, C., Vogel, M., \& Fricke, H. (2012). Safety Monitoring of new implemented approach procedures by means of radar data analysis. 5th International Conference on Research in Air Transportation (ICRAT), Berkeley.

Transport Canada, 1993. Aerodrome standards and recomended practices. In, A.N.S. (Ed.), Requirements (4th ed.). Ottawa, Ontario: Transport Canada.

Valdés, A., María, R., Comendador, G., Gordún, M., \& Nieto, S. (2011). The development of probabilistic models to estimate accident risk (due to runway overrun and landing undershoot) applicable to the design and construction of runway safety areas. Safety Science, 49, 633-650.

Wong, D.K. Y., Pitfield, D. E., Caves, R. E., \& Appleyard, A. J. (2009a). The development of a more risk-sensitive and flexible airport safety area strategy: Part I. The development of an improved accident frequency model. Safety Science, 47, 903-912.

Wong, D. K. Y., Pitfield, D. E., Caves, R. E., \& Appleyard, A. J. (2009b). The development of a more risk-sensitive and flexible airport safety area strategy: Part II. Accident location analysis and airport risk assessment case studies. Safety Science, 47, 913-924. 